\title{
Electrocardiographic findings of methanol toxicity: a cross-sectional study of 356 cases in Iran
}

\author{
Mohammad Hossein Nikoo', Alireza Arjangzadeh², Maryam Pakfetrat ${ }^{3}$, Shahrokh Sadeghi Boogar ${ }^{4}$, \\ Vahid Mohammadkarimi ${ }^{4}$, Vahid Reza Ostovan ${ }^{5,6}$, Zohre Khodamoradi ${ }^{4}$, Jamshid Roozbeh ${ }^{3}$, \\ Mohammadreza Khalilii, ${ }^{5,6}$, Farnaz Kamali Haghighi Shirazi $i^{4}$, Paryia Kouhi ${ }^{4}$ and Seyed Taghi Heydari ${ }^{7^{*}}$ (D)
}

\begin{abstract}
Background: Methanol is widely used in industry; however, methanol poisoning is not common. In this regard, a number of outbreaks have been recently reported due to inappropriate processing of alcoholic beverages. Shiraz, a city located in the southern part of Iran, faced one of such outbreaks in 2020 during COVID-19 pandemic. There is no sufficient literature on the electrocardiographic findings in methanol toxicity. This study aimed to address this gap in the literature.

Method: A total of 356 cases with methanol toxicity referred to Shiraz University of Medical Science Tertiary Hospitals (Faghihi and Namazi) in March and April, 2020. The clinical findings of blindness and impaired level of consciousness, lab data such as arterial blood gas, electrolytes, and creatinine, and the most common findings from ECGs were collected.

Results: The most common ECG findings were J point elevation (68.8\%), presence of U wave (59.2\%), QTc prolongation (53.2\% in males and $28.6 \%$ in females), and fragmented QRS (33.7\%). An outstanding finding in this study was the presence of myocardial infarction in $5.3 \%$ of the cases. This finding, to the best of our knowledge, has only been reported in a few case reports. Brugada pattern (8.1\%) and Osborn wave (3.7\%) were the other interesting findings.

In multivariate analysis, when confounding factors were adjusted, myocardial infarction, atrioventricular conduction disturbances, sinus tachycardia, and the prolonged QTC $>500$ msecond were four independent factors correlated with methanol toxicity severity measured with arterial blood $\mathrm{PH}$ on arterial blood gas measurements, with odds ratios of $12.82,4.46,2.32$ and $3.15(P<0.05$ for all), respectively.

Conclusion: Electrocardiographic variations during methanol intoxication are remarkable and well-correlated with poisoning severity. Myocardial infarction was an egregious and yet a common concerning finding in this sample, which need to be ruled out in methanol toxicity.
\end{abstract}

Keywords: Methanol toxicity, ECG, Myocardial infarction, Iran

\footnotetext{
* Correspondence: heydari.st@gmail.com

${ }^{7}$ Health Policy Research Center, Institute of Health, Shiraz University of

Medical Sciences, Building No.2.8th Floor School of Medicine Zand Avenue,

P.O.Box:71345-1877, Shiraz, Iran

Full list of author information is available at the end of the article
}

(c) The Author(s). 2020 Open Access This article is licensed under a Creative Commons Attribution 4.0 International License, which permits use, sharing, adaptation, distribution and reproduction in any medium or format, as long as you give appropriate credit to the original author(s) and the source, provide a link to the Creative Commons licence, and indicate if changes were made. The images or other third party material in this article are included in the article's Creative Commons licence, unless indicated otherwise in a credit line to the material. If material is not included in the article's Creative Commons licence and your intended use is not permitted by statutory regulation or exceeds the permitted use, you will need to obtain permission directly from the copyright holder. To view a copy of this licence, visit http://creativecommons.org/licenses/by/4.0/. The Creative Commons Public Domain Dedication waiver (http://creativecommons.org/publicdomain/zero/1.0/) applies to the data made available in this article, unless otherwise stated in a credit line to the data. 


\section{Research background}

Methanol is an odorless alcohol with industrial application, especially in solvents [1-3]. Most of the intoxication events incidentally occurs by children and rarely as a suicidal attempt. The real toxic material is formic acid, which is a metabolite of methanol in human body and its half time is around $30 \mathrm{~h} \mathrm{[3].} \mathrm{The} \mathrm{slow} \mathrm{rate} \mathrm{of} \mathrm{metab-}$ olism of formic acid is the main cause of delayed presentation of methanol toxicity [4]. Clinical findings are blindness, renal shutdown, brain damage, and finally death, if left untreated [2, 3]. Treatments often include dialysis and ethanol or fomepizole [2]. The outbreaks of methanol toxicity, defined as three cases presenting within $72 \mathrm{~h}$, have been increasingly occurred in recent years [4]. These are possibly due to the inappropriate distill or fermentation of alcoholic beverages [5]. Common and novel misconceptions about the protective and therapeutic role of alcohol consumption for COVID-19 have unfortunately contributed to this public health problem in Iran. As a result, and given the forbidden status of alcohol in Iran, the availability of homemade alcohol, which is sometimes contaminated with methanol, has increased, leading to enhanced rates of methanol toxicity [6, 7]. After the first half of March 2020, Shiraz University of Medical Sciences (SUMS) faced the methanol toxicity outbreak, which was roughly associated with the first days of Covid-19 pandemic; however, it was nearly faded in second decade of April. The reported numbers as well as mortality and morbidity rates were shockingly high.

Cardiology service was involved in the care of these patients and provided valuable data about their management and their ECG findings. To date, Jaff's et al. study on nine patients with methanol toxicity in 2014, and Sanaei-Zade's et al. (2013) study on 42 were two studies with the largest sample sizes analyzing the ECG findings attributed to methanol toxicity $[8,9]$. Accordingly, this study is the largest study reporting the ECG findings from methanol toxicity. This study aimed to describe the most common ECG findings among patients with methanol toxicity and their association with the severity of intoxication.

\section{Methods}

This is a cross-sectional study on 356 patients with methanol intoxication and were referred to Shiraz University of Medical Science Tertiary Hospitals (Namazi \& Faghihi) in March and April, 2020. The data were collected from the available charts by a cardiologist. The data included demographic characteristics, history, physical examination findings, lab data, and ECG (by Cardiax PC ECG). Then the ECGs were reviewed and reported by two cardiologists. The following patients met the inclusion criteria in this study: All patients who used the known alcoholic beverage with proved methanol impurity and developed expected clinical findings. Exclusion criteria were previous myocardial infarction, supraventricular or ventricular arrhythmias, CABG, any known genetic cardiac disease such as Brugada, long QT syndrome, and short QT syndrome.

The history and clinical data included the chronicity of alcohol usage, use of other substances, cardiac and noncardiac comorbidities, blindness, altered level of consciousness, and death and GCSS (Glasgow Coma Score Scale) for altered level of consciousness. Gathered Laboratory variables were arterial blood gas measurements, renal function measures, electrolytes, and blood sugar.

There are some reports on the following ECG parameters: some basic interpretations (rhythm, rate, axis, hypertrophy and enlargement), relatively new findings on methanol toxicity (ST elevation myocardial infarction and atrioventricular conductance disturbances), repolarization variants (J elevation, early repolarization [10], Brugada pattern [11], U wave, QTc prolongation, QT dispersion (QTD), the slope of terminal part of $\mathrm{T}$ wave (TTerm SL) [12], and Osborn wave [13]), and depolarization abnormalities (Bundle Branch Block, low voltage $\mathrm{QRS}$, poor $\mathrm{R}$ wave progression, and fragmented QRS [14]).

Myocardial infarction was defined as typical ST elevation in a group of ECG leads, which face the corresponding myocardial wall with evolutionary changes and is associated with a raise in troponin level and chest pain complaint [15]. Moreover, the definition for renal failure is based on creatine above $1.4 \mathrm{mg} / \mathrm{dl}$ [16].

The patients in the present study were categorized according to Hassanian-Moghaddam et al., who introduced $\mathrm{PH}<7$ as a marker of poor prognosis and severe acidosis [17]. The focus of this study is on the ECG findings of a large population of the patients with methanol toxicity. In this study, $\mathrm{PH}<7$ (measured by OPTI medical blood gas and electrolyte analyzers) was called severe acidosis and used as an index of severity for methanol toxicity. The association between acidemia and ECG findings were studied using univariate and multiple variables for a logistic regression model.

\section{Statistical analysis}

Statistical Package for the Social Sciences Version 21.0 (SPSS Inc., Chicago, IL, USA) was used to analyze the data. Frequency (\%) was used for categorical variable such as sex, alcohol dependency, comorbidity, ECG finding. Also, mean \pm standard deviation was used for age and laboratory finding. Chi-square test was used to assess the relationships between PH and ECG variables in methanol toxicity. Furthermore, odds ratio (OR) and corresponding confidence interval $(95 \% \mathrm{CI}$ ) was calculated by univariate logistic regression. Multiple logistic 
regression was performed to determine the independent relationship between PH and ECG variables. $P<0.05$ was considered to be statistically significant.

\section{Results}

Among the 356 patients, 328 (89.9\%) persons were male, and male/female ratio was 9.2. The mean age of the participants was $32.76 \pm 10.61$ with an age range of $15-72$ years old. Moreover, $44.7 \%$ of the participants used alcohol regularly, at least once a week; hence, more than half of the patients used alcohol infrequently or for the first time. The concurrent use of the others substances was observed in $9.5 \%$ of the participants, with opium as the most common concurrently used substance. Comorbidities were also observed in $12 \%$ of the patients $(6.5 \%$ cardiac and $5.6 \%$ non-cardiac cases). The mortality rate in our academic and well-experienced centers to manage arrhythmia and other cardiac complications reached $16.6 \%$ (59 persons). The most common clinical presentation was visual impairment, as reported for 251 persons (70.5\%). The sinus rhythm was observed in $95.8 \%$ of the participants, and only $4.2 \%$ of these individuals were found to have other rhythms such as atrial fibrillation and low atrial rhythm (Table 1). Arterial blood gas and biochemical profile were also measured, and the reports were summarized in Table 2.

\section{Univariate analysis}

In the univariate analysis, the patients with QTc $>500$ had more serious acidosis $(\mathrm{OR}=3.92$; 95\% CI: $2.17-7.07$; $P<0.001)$. This higher acidotic $\mathrm{PH}$ was observed in QTD $>40 \quad(\mathrm{OR}=1.80 ; 95 \% \quad \mathrm{CI}: \quad 1.05-3.09 ; \quad P=0.032)$, Atrioventricular block $(\mathrm{OR}=9.48$; 95\% CI: 2.76-32.55, $P<0.001)$, sinus tachycardia (OR $=2.03 ; 95 \% \mathrm{CI}: 1.14-$ 3.63, $P<0.026)$, Brugada pattern $(\mathrm{OR}=3.30 ; 95 \% \mathrm{CI}$ : 1.27-8.57; $P=0.01$ ), ST elevation Myocardial Infarction $(\mathrm{OR}=9.93$; 95\% CI: 3.57-27.58, $P<0.001)$, and Bundle Branch Block ( $\mathrm{OR}=2.86,95 \%$ CI: $1.24-6.63 ; P=0.011)$. Furthermore, there was no relationship between severe acidosis with $\mathrm{T}$ slope, J elevation, poor $\mathrm{R}$ wave progression, and low voltage QRS $(P>0.05)$ (Table 3$)$.

\section{Multivariate analysis}

In multiple logistic regression, there was a statistically significant relationship between severe acidosis $(\mathrm{PH}<7)$ with $\mathrm{QTc}>500 \quad(\mathrm{OR}=3.15, \mathrm{CI}=95 \%$ : $1.55-6.40 ; \quad P=$ 0.001), Atrioventricular block (OR $=4.46$; CI 95\%: $1.03-$ 19.23; $P=0.045)$, sinus tachycardia $(\mathrm{OR}=2.32$; CI $95 \%$ : $1.19-4.53 ; P=0.014)$, and ST elevation myocardial infarction $(\mathrm{OR}=12.82 ; \quad \mathrm{CI}$ 95\%: 3.82-43.11; $P<0.001)$ (Table 3).

\section{Discussion}

Methanol intoxication, when sever enough, causes many electrocardiographic changes. J point elevation and $U$ wave are most frequent (Fig. 1), While others like QTc more than $500 \mathrm{~m}$-second tends to be an index of severity (Table 3).

A total number of 356 patients were included in this study, a majority of whom were male. This can be explained by the participants' cultural background and relevant social stigma of alcohol usage for women in Iran. Compared to previous outbreaks $[18,19]$, the age distribution of the population was broader as the study included teenagers as well as senior patients who were in their 70's in some cases. The involvement of the youths may be a matter of concern for social activists in Iran.

In this study, interesting finding were myocardial infarction, AVB and sinus tachycardia, and QT $>500$, all of which predispose the patients to arrythmia. The mechanism of arrythmia is tightly related to acidosis. Acidosis is an obvious biochemical marker with regard to its several mechanisms. Formic acid makes a pivotal contribution to the PH drop, which causes hyperkalemia when acidosis makes potassium to shift out of cells. Another reason for high potassium level may be oliguria, which prevent potassium loss in urine. Another consequence of acidosis seems to be hypercalcemia caused by a decrease in binding to protein under this condition. The extra amount of both ions contributes to arrhythmia mechanism [20].

Different mortality rates have been reported for methanol intoxication. The reason may be controversy in definitions. Taiwan nationwide survey showed $40 \%$ long-term mortality [21]; however, a study from UK reported a 11\% rate [8]. Another research with the rate of $40 \%$ was performed by Sanaei-Zade et al. [9]. The mortality rate in our series was slightly $<17 \%$, which seems to be more comparable to a study by Jaff et al. [8]; however, this is an in-hospital mortality in two referral centers, and the ones related to the outpatient cases were not included. The mortality and ocular and brain damage rates are in agreement with some previous outbreak reports [19, 22-24].

Although the most common finding in a previous report from the UK [8] was sinus tachycardia, most cases in this study seemed to have normal heart rate; however, the tachycardia proved to be a severity index in the present research. In this regard, the lower prevalence may be due to less severe intoxication in our patients. The heart rate $>100$ was observed in $25.3 \%$ of the sample, which was nearly six times as great as bradycardia (rate $<60$ ). In other words, about three quarter of our cases were at a normal range in this regard. 
Table 1 Clinical variables and ECG findings among methanol toxicity

\begin{tabular}{|c|c|c|c|c|}
\hline \multirow{2}{*}{ Alcohol dependency } & & & Frequency & Percent \\
\hline & & & 142 & 39.9 \\
\hline \multicolumn{2}{|l|}{ Other substance abuse } & & 32 & 9.0 \\
\hline \multirow[t]{13}{*}{ Comorbidity } & Cardiac & HTN & 18 & 5.1 \\
\hline & & $\mathrm{PCl}$ & 4 & 1.1 \\
\hline & & PTE & 1 & 0.3 \\
\hline & Non-cardiac & $\mathrm{DM}$ & 6 & 1.7 \\
\hline & & Seizure & 2 & 0.6 \\
\hline & & Probably Asthma & 3 & 0.8 \\
\hline & & Malignancy & 2 & 0.6 \\
\hline & & Psychiatry & 2 & 0.6 \\
\hline & & Hemophilia & 1 & 0.3 \\
\hline & & Down syndrome & 1 & 0.3 \\
\hline & & Fatty liver & 1 & 0.3 \\
\hline & & Splenectomy & 1 & 0.3 \\
\hline & & Hypothyroid & 1 & 0.3 \\
\hline \multicolumn{3}{|l|}{ Decreased visual acuity } & 251 & 70.5 \\
\hline \multicolumn{3}{|l|}{ Death } & 59 & 16.6 \\
\hline \multicolumn{3}{|l|}{ Renal failure } & 137 & 38.5 \\
\hline \multirow[t]{3}{*}{ GCSS } & \multicolumn{2}{|l|}{ GCSS 15} & 252 & 72.6 \\
\hline & \multicolumn{2}{|l|}{ GCSS 3} & 48 & 13.8 \\
\hline & \multicolumn{2}{|l|}{ GCSS 4-14 } & 47 & 13.5 \\
\hline \multirow[t]{4}{*}{ Rhythm } & \multicolumn{2}{|l|}{ Sinus } & 341 & 98.0 \\
\hline & \multicolumn{2}{|c|}{ Atrial fibrillation } & 3 & 0.9 \\
\hline & \multicolumn{2}{|c|}{ Low atrial rhythm } & 2 & 0.6 \\
\hline & \multicolumn{2}{|c|}{ Accelerated idio-ventricular rhythm } & 2 & 0.6 \\
\hline \multirow[t]{3}{*}{ Rate } & \multicolumn{2}{|l|}{ Normal } & 251 & 71.3 \\
\hline & \multicolumn{2}{|l|}{$>100$} & 89 & 25.3 \\
\hline & \multicolumn{2}{|l|}{$<60$} & 12 & 3.4 \\
\hline \multirow[t]{4}{*}{ Axis } & \multicolumn{2}{|l|}{ Normal } & 296 & 83.5 \\
\hline & \multicolumn{2}{|l|}{ Right } & 36 & 10.1 \\
\hline & \multicolumn{2}{|l|}{ Left } & 19 & 5.3 \\
\hline & \multicolumn{2}{|l|}{ Extreme } & 4 & 1.1 \\
\hline Hypertrophy and enlargement & RV & & 9 & 2.6 \\
\hline & RA & & 8 & 2.3 \\
\hline & LV & & 6 & 1.7 \\
\hline & $\mathrm{LA}$ & & 9 & 2.6 \\
\hline & Mixed & & 8 & 2.3 \\
\hline Infarction & & & 19 & 5.5 \\
\hline AVB & First degree & & 11 & 3.2 \\
\hline & Third degree & & 1 & 0.3 \\
\hline J point elevation & & & 245 & 70.6 \\
\hline Brugada pattern & Type 1 & & 4 & 1.2 \\
\hline & Type 2 & & 3 & 0.9 \\
\hline & Type 3 & & 13 & 3.7 \\
\hline
\end{tabular}


Table 1 Clinical variables and ECG findings among methanol toxicity (Continued)

\begin{tabular}{llll}
\hline & & Frequency & Percent \\
\hline Early repolarization & & 168 & 48.4 \\
Osborn wave & $<=500$ & 13 & 3.7 \\
QTc & $>500$ & 278 & 80.1 \\
& $<40$ & 69 & 19.9 \\
QTd & $>=40$ & 179 & 41.6 \\
& & 168 & 38.4 \\
Fragmented QRS & RBBB & 120 & 34.7 \\
BBB & LBBB & 24 & 7.0 \\
& IVCD & 2 & 0.6 \\
U wave & & 2 & 0.6 \\
Poor R progression & & 212 & 7.3 \\
Low voltage & & 14 & 4.3 \\
\hline
\end{tabular}

HTN Hypertension, DM Diabetes Mellites, PCI Percutaneous Coronary Intervention, PTE History of Pulmonary Thrombo-Emboli, BBB Bundle branch block, STEMI ST segment elevation myocardial infarction, AVB Atrioventricular conduction block

Although there are few case reports on the myocardial infarction in methanol toxicity [23], our survey was the first study, which could determine the prevalence of this complication. However, the exact pathophysiologic mechanism yet requires further research. We proposed the following hypotheses: (1) This infarction is possible in relatively young patients with no usual risk factors for atherosclerosis [24]; (2) severe acidosis causes bleeding due to a decrease in fibrinogen level. In-situ thrombosis may sometimes occur with ongoing disseminated intravascular coagulation and possible myocardial infarction [25]; (3) Possible pathophysiologic mechanism may be endothelial dysfunction, which is a known entity in reduced extracellular $\mathrm{PH}$, however such a dysfunction will end in vasodilation frustratingly [26]; and (4) Acidosis causes vasodilatation; thus, spasm, as a mechanism of myocardial infarction cannot be blamed [27]. Such hypotheses necessitate further investigation and research.
In our study, J point elevation was the most prevalent finding; therefore, repolarization abnormalities were to be categorized as early repolarization, Brugada phenocopy, and QT prolongation syndrome. According to the literature, arrhythmia can be predicted in accordance with the ECG findings such as QT prolongation, Brugada pattern, negative terminal portion of $\mathrm{P}$ wave in V1, inter-atrial block, and so on [28]. Another newly introduced observation on ECG is QRS fragmentation, which is correlated with mortality in myocardial infarction in recent surveys [29]. The only variable which was consistently correlated with the severity of disease was QTc prolongation $>500$. The QT prolongation was reported in mostly all the previous studies [e.g., [3, 30, 31]]. However, its significance could not be emphasized due to the lower volume in older reports. QTc prolongation is the most commonly-used indicator; however, prolongation $<500 \mathrm{msec}$. May be interpreted doubtfully.

Table 2 Laboratory finding in methanol toxicity

\begin{tabular}{llll}
\hline Variables & $\mathrm{N}$ & Mean & Standard Deviation \\
\hline PH & 349 & 7.14 & 0.22 \\
Bicarbonate (meq/l) & 349 & 11.14 & 8.02 \\
Partial Pressure of Carbon Dioxide (torr) & 349 & 27.82 & 13.81 \\
Oxygen saturation (\%) & 337 & 90.50 & 10.43 \\
Blood urea nitrogen (mg/dl) & 342 & 14.18 & 10.83 \\
Creatinine (mg/dl) & 342 & 1.43 & 0.63 \\
Sodium (meq/l) & 337 & 142.17 & 4.21 \\
Potassium (meq/l) & 332 & 4.83 & 1.17 \\
Calcium (mg/dl) & 251 & 9.55 & 0.77 \\
Magnesium (mg/dl) & 177 & 2.41 & 1.55 \\
Blood sugar $(\mathbf{m g} / \mathbf{d l})$ & 311 & 143.97 & 95.85 \\
\hline
\end{tabular}


Table 3 Association between PH and ECG variables in methanol toxicity with univariate and multiple logistic regression

\begin{tabular}{|c|c|c|c|c|c|c|c|c|}
\hline & & $\mathrm{PH}$ & & $P-$ & & $P-$ & & $P-$ \\
\hline & & $>7$ & $<=7$ & & $\begin{array}{l}\text { C1) } \\
\text { Univariate }\end{array}$ & & & \\
\hline QTC & $<500$ & $238(85.6)$ & $40(14.4)$ & $<0.001$ & 1 & - & 1 & - \\
\hline & $>=500$ & $41(60.3)$ & $27(39.7)$ & & $3.92(2.17-7.07)$ & $<0.001$ & $3.15(1.55-6.40)$ & 0.001 \\
\hline QT dispersion & $<40$ & $153(85.0)$ & $27(15.0)$ & 0.032 & 1 & - & 1 & - \\
\hline & $>=40$ & $126(75.9)$ & $40(24.1)$ & & $1.80(1.05-3.09)$ & 0.034 & $1.19(0.62-2.26)$ & 0.603 \\
\hline T slope & $<69$ & $184(81.1)$ & $43(18.9)$ & 0.700 & 1 & - & 1 & - \\
\hline & $>=70$ & $96(79.3)$ & $25(20.70$ & & $1.11(0.64-1.93)$ & 0.700 & $2.28(1.11-4.69)$ & 0.488 \\
\hline AVB & No & $275(82.6)$ & $58(17.4)$ & $<0.001$ & 1 & - & 1 & - \\
\hline & Yes & $4(33.3)$ & $8(66.7)$ & & $9.48(2.76-32.55)$ & $<0.001$ & $4.46(1.03-19.23)$ & 0.045 \\
\hline Rate & $60-100$ & $208(84.2)$ & 39 (15.8) & 0.026 & 1 & - & 1 & - \\
\hline & $<59$ & $8(66.7)$ & $4(33.3)$ & & $2.67(0.77-8.29)$ & 0.123 & $1.8(0.371-8.70)$ & 0.467 \\
\hline & $>100$ & $63(72.4)$ & $24(27.6)$ & & $2.03(1.14-3.63)$ & 0.017 & $2.32(1.19-4.53)$ & 0.014 \\
\hline Brugada & No & $268(82.0)$ & $59(18.0)$ & 0.010 & 1 & - & 1 & - \\
\hline & Yes & $11(57.9)$ & $8(42.1)$ & & $3.30(1.27-8.57)$ & 0.014 & $2.91(0.94-8.99)$ & 0.063 \\
\hline J elevation & No & $87(85.3)$ & $15(14.7)$ & 0.156 & 1 & - & 1 & - \\
\hline & Yes & $192(78.7)$ & $52(21.3)$ & & $1.57(0.84-2.94)$ & 0.159 & $1.16(0.55-2.48)$ & 0.693 \\
\hline STEMI $^{a}$ & No & $273(83.2)$ & $55(16.8)$ & $<0.001$ & 1 & - & 1 & - \\
\hline & Yes & $6(33.3)$ & $12(66.7)$ & & $9.93(3.57-27.58)$ & $<0.001$ & $12.82(3.82-43.11)$ & $<0.001$ \\
\hline $\mathrm{BBB}^{\mathrm{a}}$ & No & $26182.1)$ & $57(17.9)$ & 0.011 & 1 & - & 1 & - \\
\hline & Yes & $16(61.5)$ & $10(38.5)$ & & $2.86(1.24-6.63)$ & 0.014 & $2.48(0.92-6.66)$ & 0.073 \\
\hline Poor progression & No & $260(81.5)$ & $59(18.5)$ & 0.101 & 1 & - & 1 & - \\
\hline & Yes & $17(68.0)$ & $8(32.0)$ & & $2.07(0.86-2.03)$ & 0.107 & $2.41(0.88-6.56)$ & 0.086 \\
\hline Low voltage & No & $267(80.9)$ & $63(19.1)$ & 0.398 & 1 & - & 1 & - \\
\hline & Yes & $10(71.4)$ & $4(28.4)$ & & $1.70(0.52-5.58)$ & 0.385 & $1.93(0.50-7.54)$ & 0.343 \\
\hline
\end{tabular}

${ }^{\mathrm{a} B B B}$ Bundle branch block, STEMI ST segment elevation myocardial infarction, AVB Atrioventricular conduction block, $P$ value less than 0.05 considered significant

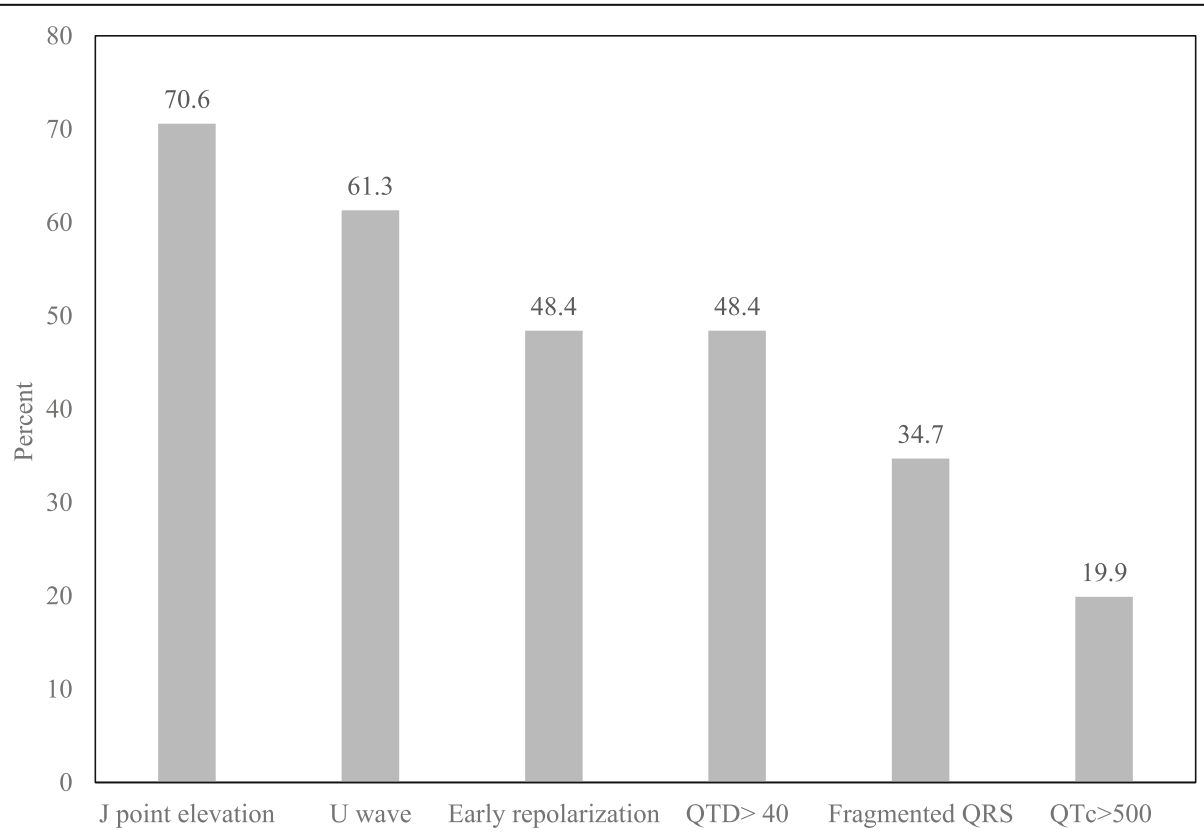

Fig. 1 The most common ECG findings in methanol toxicity 
Accordingly, we approached the values $>500$ as an independent marker of severity [32, 33].

We noted two type 1 Brugada ECG pattern in two brain-dead patients as terminal event before their arrest. This finding has been reported in some critical situations with deadly consequences. As an example, similar pattern has observed in some head injured patients before their death in Neurosurgery Intensive care unit. There are also reports of same pattern during Propofol infusion [34, 35].

The best independent ECG indicators of methanol toxicity severity were QTc $>500$ and heart rate $>100$. Interestingly, severe poisoning was strongly associated with myocardial infarction and atrioventricular block in our survey (Table 3 ).

\section{Research limitations}

The research design is cross-sectional so that it suffers from lack of long-term perspectives. Our diagnosis on myocardial infarction was based on the ECG finding, evolutionary changes, and enzyme rising in those with chest pain or chest pain equivalents; however, it disregarded coronary angiography and cardiac MRI.

\section{Conclusion}

This cross-sectional survey was conducted on 356 patients admitted to hospitals due to methanol toxicity and examined the most common ECG findings and their association with $\mathrm{PH}$ as a marker of methanol intoxication severity. In this study, myocardial infarction, AVB and sinus tachycardia, and QT $>500$ were four independent markers of severity.

\section{Abbreviations \\ COVID-19: Coronavirus; ECG: Electrocardiogram; SUMS: Shiraz University of Medical Sciences; BBB: Bundle branch block; STEMI: ST segment elevation myocardial infarction; AVB: Atrioventricular conduction block; msecond: Millisecond; UK: United Kingdom; TTerm SL: Slop of terminal part of T wave; GCSS: Glasgow coma score scale; QTc: Corrected QT; QTD: QT dispersion; HTN: Hypertension; DM: Diabetes Mellites; PCl: Percutaneous coronary intervention; PE: History of pulmonary Thrombo-emboli; CABG: Coronary artery bypass grafting}

\section{Acknowledgements}

The present study was supported the Vice-chancellor for Research, Shiraz University of Medical Sciences, Shiraz, Iran. The authors would also like to show our great appreciation for help by Mohammadali Nikoo in scientific writing.

\section{Authors' contributions}

MHN, STH, AA contributed in analyzed the data, and interpreted the results, wrote the manuscript drafting. MP, ShSB contributed in interpretation the results and designed the study. VRO, ZKh, JR, MRK, FKHSh, PK contributed in interpretation the results wrote the manuscript drafting. All authors have read and approved the manuscript.

\section{Funding}

The research grant provided by Research Deputy of Shiraz University of Medical Sciences (number: 98-01-01-22074). Funding body of the study did not play any role in the design of the study, collection, analysis, and interpretation of data and in writing the manuscript.

\section{Availability of data and materials}

The datasets used and/or analyzed during the current study available from the corresponding author on reasonable request.

\section{Ethics approval and consent to participate}

This study was approved by the ethics committee of Shiraz University of Medical Sciences (IR.SUMS.REC.1399.059). There were some problems with literacy, visual acuity and understanding of participation in data gathering, accordingly we talk to everyone in best simple way and then they sign the written informed consent. If the patient was under legal age, has visual impairment or unlettered, the parents or guardians included in explanation session and they sign instead. However, any participant is included only if the consent is existed and the ethical committee are aware of the situation.

Consent for publication

Not Applicable.

\section{Competing interests}

The authors declare that they have no competing interests.

\section{Author details}

${ }^{1}$ Non-communicable Disease Research Centre, Shiraz University of Medical Sciences, Shiraz, Iran. ${ }^{2}$ Cardiology Department, Shiraz University of Medical Sciences, Shiraz, Iran. ${ }^{3}$ Department of Internal Medicine, Shiraz

Nephro-Urology Research Center, Shiraz University of Medical Sciences, Shiraz, Iran. ${ }^{4}$ Department of Internal Medicine, School Of Medicine, Shiraz University of Medical Sciences, Shiraz, Iran. ${ }^{5}$ Clinical Neurology Research Center, Shiraz University of Medical Sciences, Shiraz, Iran. ${ }^{6}$ Poostchi Eye Research Centre, Ophthalmology Department, Shiraz University of Medical Sciences, Shiraz, Iran. ${ }^{7}$ Health Policy Research Center, Institute of Health, Shiraz University of Medical Sciences, Building No.2.8th Floor School of Medicine Zand Avenue, P.O.Box:71345-1877, Shiraz, Iran.

Received: 9 June 2020 Accepted: 27 August 2020

Published online: 14 September 2020

\section{References}

1. Chan AP, Chan TY. Methanol as an unlisted ingredient in supposedly alcohol-based hand rub can pose serious health risk. Int J Environ Res Public Health. 2018;15(7):1440,

2. Ashurst JV, Nappe TM. Methanol toxicity; 2019

3. Ahmed F, Khan NU, Ali N, Feroze A. Methanol poisoning: 27 years experience at a tertiary care hospital; 2017.

4. Holt NR, Nickson CP. Severe methanol poisoning with neurological sequelae: implications for diagnosis and management. Intern Med J. 2018; 48(3):335-9.

5. Beauchamp G, Valento M, Kim J. Toxic alcohol ingestion: prompt recognition and management in the emergency department [digest]. Emerg Med Pract. 2016;18(9 Suppl Points \& Pearls):S1-2.

6. Eghbali H, Mostafazadeh B, Ghorbani M, Behnoush B. Neurologic complications of methanol poisoning: a Clinicoepidemiological report from poisoning treatment centers in Tehran, Iran. Asia Pac J Med Toxicol. 2015: 4(1):47-50.

7. Zamani N, Rafizadeh A, Hassanian-Moghaddam H, Akhavan-Tavakoli A, Ghorbani-Samin M, Akhgari M, Shariati S. Evaluation of methanol content of illegal beverages using GC and an easier modified Chromotropic acid method; a cross sectional study. Substance Abuse Treat Prev Policy. 2019; 14(1):56.

8. Jaff Z, McIntyre WF, Yazdan-Ashoori P, Baranchuk A. Impact of methano intoxication on the human electrocardiogram. Cardiol J. 2014;21(2):170-5.

9. Sanaei-Zadeh $\mathrm{H}$, Emamhadi M, Farajidana H, Zamani N, Amirfarhangi A. ECG as mortality predictor in methanol poisoning. Arh Hig Rada Toksikol. 2013; 64:265-71.

10. Derval N, Shah A, Jaïs P. Definition of early repolarization: a tug of war. In: Am Heart Assoc; 2011.

11. Sieira J, Brugada P. The definition of the Brugada syndrome. Eur Heart J. 2017;38(40):3029-34

12. Pavri BB, Siu H, Andrikopoulou E, Ho R, DeCaro M. T wave slopes: a novel method for assessment OF repolarization dispersion from surface ECGS with prolonged QT as compared to normal ECGS. J Am Coll Cardiol. 2014;63(12 Supplement):A1638. 
13. Maruyama M, Kobayashi Y, Kodani E, Hirayama Y, Atarashi H, Katoh T, Takano T. Osborn waves: history and significance. Indian Pacing Electrophysiol J. 2004;4(1):33.

14. Supreeth R, Francis J. Fragmented QRS-its significance. Indian Pacing and Electrophysiol J. 2020;20(1):27-32.

15. Thygesen K, Alpert JS, Jaffe AS, Chaitman BR, Bax JJ, Morrow DA, White HD. Fourth universal definition of myocardial infarction (2018). J Am Coll Cardiol. 2018;72(18):2231-64

16. Lee CY, Chang EK, Lin JL, Weng CH, Lee SY, Juan KC, Yang HY, Lin C, Lee SH, Wang IK, et al. Risk factors for mortality in Asian Taiwanese patients with methanol poisoning. Ther Clin Risk Manag. 2014;10:61-7.

17. Hassanian-Moghaddam H, Pajoumand A, Dadgar S, Shadnia S. Prognostic factors in methanol poisoning. Hum Exp Toxicol. 2007;26(7):583-6.

18. Naraqi S, Dethlefs R, Slobodniuk R, Sairere J. An outbreak of acute methyl alcohol intoxication. Aust NZ J Med. 1979;9(1):65-8.

19. Aghababaeian H, Araghi Ahvazi L, Ostadtaghizadeh A. The methanol poisoning outbreaks in Iran 2018. Alcohol Alcohol. 2019;54(2):128-30.

20. Mozos I. Laboratory markers of ventricular arrhythmia risk in renal failure. Biomed Res Int. 2014;2014:509204.

21. Chung J-Y, Ho C-H, Chen Y-C, Chen J-H, Lin H-J, Wang J-J, Hsu C-C, Huang C-C. Association between acute methanol poisoning and subsequent mortality: a nationwide study in Taiwan. BMC Public Health. 2018;18(1):985.

22. Hovda KE, Hunderi OH, TAFJORD AB, Dunlop O, Rudberg N, Jacobsen D. Methanol outbreak in Norway 2002-2004: epidemiology, clinical features and prognostic signs. J Intern Med. 2005;258(2):181-90.

23. Chow E, Khosla A, Berman L. Methanol Induced ST Elevation and Brain Death. D46 critical care case reports: toxicology and poisonings. American Thoracic Society; 2018. p. A6926. https://scholar.google.com/scholar?hl= en\&as_sdt $=0 \% 2 C 5 \& q=C h o w+E \% 2 C+$ Khosla $+A \% 2 C+$ Berman+L.+Methanol+ Induced+ST+Elevation+and+Brain+Death.+In\%3A+D46+Critical+care+case+ reports\%3A+toxicology+and+poisonings.+edn\%3A+American+Thoracic+ Society\&btnG=.

24. Berenson GS, Srinivasan SR, Bao W, Newman WP, Tracy RE, Wattigney WA. Association between multiple cardiovascular risk factors and atherosclerosis in children and young adults. N Engl J Med. 1998;338(23):1650-6.

25. Kimmoun A, Novy E, Auchet T, Ducrocq N, Levy B. Hemodynamic consequences of severe lactic acidosis in shock states: from bench to bedside. Crit Care. 2016;19(1):175.

26. Crimi E, Taccone FS, Infante T, Scolletta S, Crudele V, Napoli C. Effects of intracellular acidosis on endothelial function: an overview. J Crit Care. 2012; 27(2):108-18.

27. Celotto A, Capellini V, Baldo C, Dalio M, Rodrigues A, Évora PRB. Effects of acid-base imbalance on vascular reactivity. Braz J Med Biol Res. 2008;41(6): 439-45.

28. Mozos I, Caraba A. Electrocardiographic predictors of cardiovascular mortality. Dis Markers. 2015;2015:727401.

29. Q-h S, Hsu C-C, J-p L, Hong T, Huo Y. Correlation between fragmented QRS and the short-term prognosis of patients with acute myocardial infarction. J Zhejiang Univ Sci B. 2014;15(1):67-74.

30. Paasma R, Hovda KE, Tikkerberi A, Jacobsen D. Methanol mass poisoning in Estonia: outbreak in 154 patients. Clin Toxicol. 2007;45(2):152-7.

31. Zakharov S, Pelclova D, Urban P, Navratil T, Diblik P, Kuthan P, Hubacek JA, Miovsky M, Klempir J, Vaneckova M. Czech mass methanol outbreak 2012: epidemiology, challenges and clinical features. Clin Toxicol. 2014;52(10): 1013-24.

32. Issa Z, Miller JM, Zipes DP. Clinical Arrhythmology and electrophysiology: a companion to Braunwald's heart disease E-book: expert consult: online and print: Elsevier health sciences; 2012.

33. Johnson JN, Ackerman MJ. QTc: how long is too long? Br J Sports Med. 2009;43(9):657-62.

34. Vernooy K, Delhaas T, Cremer OL, Di Diego JM, Oliva A, Timmermans C, Volders PG, Prinzen FW, Crijns HJ, Antzelevitch C. Electrocardiographic changes predicting sudden death in propofol-related infusion syndrome. Heart Rhythm. 2006;3(2):131-7.

35. Weiner JB, Haddad EV, Raj SR. Recovery following Propofol-associated Brugada electrocardiogram. Pacing Clin Electrophysiol. 2010;33(4):e39-42.

\section{Publisher's Note}

Springer Nature remains neutral with regard to jurisdictional claims in published maps and institutional affiliations.

Ready to submit your research? Choose BMC and benefit from:

- fast, convenient online submission

- thorough peer review by experienced researchers in your field

- rapid publication on acceptance

- support for research data, including large and complex data types

- gold Open Access which fosters wider collaboration and increased citations

- maximum visibility for your research: over $100 \mathrm{M}$ website views per year

At $\mathrm{BMC}$, research is always in progress.

Learn more biomedcentral.com/submissions 